National Marine

Fisheries Service

Fishery Bulletin

Spencer F. Baird

NOAA

as established in 1881 ๙

\begin{abstract}
Sea turtles are exposed to numerous anthropogenic threats at sea, and exposure to these threats can result in the stranding of dead animals ashore. In addition to environmental conditions, rate of carcass decomposition is an important but little studied factor in determining whether a sea turtle carcass will strand. Most carcasses of sea turtles collected for research are frozen upon retrieval, and the effects of freezing have not been studied. We compared the decomposition rate of unfrozen and previously frozen carcasses of green (Chelonia mydas) and Kemp's ridley (Lepidochelys kempii) sea turtles recovered from cold-stunning events. Species had the greatest influence on the rate of decomposition, with green sea turtles becoming positively buoyant and decomposing at a faster rate than Kemp's ridley sea turtles. The effects of freezing were negligible, indicating that frozen carcasses may be a suitable replacement for fresh carcasses in research studies, including studies related to decomposition of sea turtles.
\end{abstract}

Manuscript submitted 16 January 2020. Manuscript accepted 26 August 2020. Fish. Bull. 118:268-274 (2020). Online publication date: 10 September 2020. doi: 10.7755/FB.118.3.5

The views and opinions expressed or implied in this article are those of the author (or authors) and do not necessarily reflect the position of the National Marine Fisheries Service, NOAA.

\title{
Effects of freezing on decomposition of sea turtle carcasses used for research studies
}

\author{
Melissa Cook (contact author) ${ }^{1}$ \\ Jaymie L. Reneker ${ }^{2}$ \\ Redwood W. Nero ${ }^{3}$ \\ Brian A. Stacy 4 \\ David S. Hanisko'
}

Email address for contact author: melissa.cook@noaa.gov

${ }^{1}$ Southeast Fisheries Science Center National Marine Fisheries Service, NOAA 3209 Frederic Street

Pascagoula, Mississippi 39567

2 Riverside Technology Inc. Southeast Fisheries Science Center 3209 Frederic Street

Pascagoula, Mississippi 39567

\author{
${ }^{3}$ Southeast Fisheries Science Center \\ National Marine Fisheries Service, NOAA \\ Building 1021 \\ Stennis Space Center, Mississippi 39529 \\ ${ }^{4}$ Office of Protected Resources \\ National Marine Fisheries Service, NOAA \\ University of Florida \\ 2187 Mowry Road, Building 471 \\ Gainesville, Florida 32611
}

Marine animals found washed ashore (i.e., stranded) are often studied to identify and monitor causes of mortality (e.g., vessel strikes, disease, and fisheries interactions). Examinations of stranded animals can yield valuable information about threats affecting marine species like sea turtles. According to the IUCN Red List of Threatened Species (IUCN, 2019), most populations of sea turtles are vulnerable to extinction worldwide because of predominately anthropogenic threats, including the risk of becoming bycatch in fisheries, consumption of sea turtles and their eggs, habitat destruction, and climate change (Mast et al., 2005; Wallace et al., 2011). Results of studies of stranded sea turtles have improved our understanding of these threats and have contributed other valuable information related to life history, health, and disease.

After a sea turtle dies, a number of factors influence whether or not its carcass will strand ashore and become available for discovery by humans. When sea turtles are killed by vessel strikes or drown in fishing gear, they usually sink to the seafloor because gas volume within the lungs is insufficient to maintain positive buoyancy (Epperly et al., 1996). Once submerged, a carcass stays underwater until the bacteria in the gut produce enough gases (methane, hydrogen sulfide, and carbon dioxide) to float it to the surface (Vass, 2001; Mateus and Pinto, 2016). The buildup of gases can take hours, days, or weeks, depending on factors such as body composition, diet, animal size, water depth, and water temperature. A second influential period occurs if the carcass surfaces. Once on the surface, carcasses are subject to wind and currents, consumption by scavengers, and continued decomposition influenced by ambient air and water temperatures. The combination of these factors influences the beaching process and ultimately whether or not a carcass is ever found. The likelihood of shoreline deposition, or stranding probability, provides critical context for interpreting data derived from stranded animals. For example, if 
stranding probability is low, the number of strandings will also likely be low even if at-sea mortality is high.

Decomposition rate influences how long carcasses persist in the environment and, therefore, their availability for detection. In addition, decomposition affects the duration of buoyancy and drift, key factors used in determining where stranded sea turtles may have died (Nero et al., 2013). Despite their importance, decomposition rates in sea turtles have been examined in only a few studies. One challenge is the low availability of carcasses of sea turtles in conditions suitable for decomposition studies because of their protected status and various logistical constraints. Use of previously frozen carcasses is often the only feasible option for such research (Reneker et al., 2018; Santos et al., 2018). However, study of the effects of freezing and thawing on decomposition in any taxa has been limited (e.g., rats; Micozzi, 1986), and there has been no such study for sea turtles. In addition, decomposition rates may vary among sea turtle species because of differences in diet and alimentary anatomy that could also affect postmortem processes and extrapolation of results among species.

The objectives of our study were to compare decomposition rates between previously frozen and unfrozen carcasses of sea turtles and between 2 species of sea turtles with anatomical and dietary differences that could affect postmortem processes. We used the Kemp's ridley sea turtle (Lepidochelys kempii), a benthic carnivore, and the green sea turtle (Chelonia mydas), an herbivore and a hindgut fermenter with an intestine that is proportionally longer than those of carnivorous cheloniid species (Bjorndal, 1979, 1997). The overall goal of this study was to determine if frozen carcasses are a suitable replacement for fresh carcasses in studies that require carcasses of sea turtles, including research of decomposition of sea turtles.

\section{Materials and methods}

\section{Ethics statement}

This study was authorized under U.S. Fish and Wildlife Service permit number TE 676395-5. No live animals were killed or harmed for this cadaver study.

\section{Carcasses}

All carcasses used in this study were sea turtles that died during cold-stunning events in December 2017. Cold-stunning events, which occur when nearshore water temperatures fall below $10^{\circ} \mathrm{C}$, provide the most readily available source of undecomposed carcasses. Therefore, we conducted this study during winter months. The green sea turtles originated from Saint Joseph Bay in Florida, where they are known to predominantly forage on turtlegrass (Thalassia testudinum) (Foley et al., 2007). The Kemp's ridley sea turtles were from Cape Cod Bay in Massachusetts. Previous studies of cold-stunned sea turtles from this area have reported a diet of various benthic invertebrates (Innis et al., 2009).
We used 7 individuals of each species with a mean size of $26.6 \mathrm{~cm}$ straight carapace length (SCL) and a size range of 21.7-28.1 cm SCL. All turtles were determined to be dead on the basis of the absence of detectable cardiac contraction. We included only carcasses that lacked any odor or visual evidence of decomposition (e.g., bloating and scutes peeling). Three carcasses of each species were frozen immediately $\left(0^{\circ} \mathrm{C}\right)$ and kept frozen until they were shipped to the Stennis Space Center (SSC) site of the Mississippi Laboratories, NOAA Southeast Fisheries Science Center, 2-6 d later, depending on the stranding date. The remaining 4 individuals of each species were refrigerated at $3-6^{\circ} \mathrm{C}$ for 18-30 h (Kemp's ridley sea turtles) or for $5 \mathrm{~d}$ (green sea turtles). The green sea turtles that were stranded on Friday, 29 December 2017, could not be shipped until the following Tuesday because of the holiday weekend. All individuals were shipped on ice overnight $(<24 \mathrm{~h})$ to the SSC facility. The temperature in the ice chest was maintained at $1^{\circ} \mathrm{C}$ during shipping. The carcasses used in our study beached in near freezing conditions and were then stored frozen, or nearly frozen, before and during shipment. Therefore, we assumed that decomposition was minimal prior to placement of sea turtles into the tank at the beginning of the study and considered the time of this placement the start time for all observations. Frozen carcasses were thawed in a freshwater bath and warmed to $\sim 4^{\circ} \mathrm{C}$ over a period of $1-2 \mathrm{~h}$ prior to the initiation of observations of decomposition.

\section{Decomposition observations}

Experiments in which decomposition of carcasses was monitored were conducted simultaneously for all individuals of each species. The observations of Kemp's ridley sea turtles began on 13 December 2017; the observations of green sea turtles began on 3 January 2018. Decomposition was tracked in 2 phases: time until positive buoyancy was attained and time until positive buoyancy was lost. Both phases hinge on key postmortem events related to dispersal and discovery of sea turtle carcasses. For logistical reasons, the first phase was conducted within an indoor laboratory and the second was conducted in an outdoor floating pen.

We measured the time required for carcasses to float in a $1173-\mathrm{L}$ polyethylene water storage tank $(0.81 \mathrm{~m}$ wide $\times 2.34 \mathrm{~m}$ high). The tank was covered in a $0.10-\mathrm{m}$ layer of fiber insulation to reduce thermal swings from the ambient air conditions, and the depth of water in the tank was $2.31 \mathrm{~m}$. To provide controlled conditions, the tank was filled with fresh tap water obtained from the SSC facility and had a pressure of $101.33 \mathrm{kPa}$, equivalent to approximately $2.20 \mathrm{~m}$ of seawater. Temperatures were maintained near $20^{\circ} \mathrm{C}$ by using 3 thermostatically controlled $300-\mathrm{W}$ aquarium heaters, and water flow from a circulation pump kept water in the tank well mixed. Temperature was also monitored manually with a YSI- $85^{1}$ meter

\footnotetext{
${ }^{1}$ Mention of trade names or commercial companies is for identification purposes only and does not imply endorsement by the National Marine Fisheries Service, NOAA.
} 
(YSI, Yellow Springs, OH) during daily visual inspections. Status of the carcasses was also monitored with a wideangle Mobius ActionCam HD digital camera (Mobius, New York), which was mounted on the top of the tank looking down and was set to take photographs every minute. When placed into water, most carcasses sank immediately to the bottom of the tank. Five carcasses initially floated and were compressed against the bottom of the water bath to expel excess air in the lungs until negative buoyancy was attained. This treatment was intended to ensure that carcasses were similarly buoyant at the beginning of the study. Carcasses were kept in the tank until they floated to the surface.

Once carcasses became buoyant and floated to the surface, they were released in the Bay-Waveland Yacht Club harbor at $30^{\circ} 19^{\prime} 30^{\prime \prime} \mathrm{N}, 89^{\circ} 19^{\prime} 32^{\prime \prime} \mathrm{W}$ so that the final stages of decomposition could occur in a natural setting where the products of the process could dissipate and be ameliorated by the environment. This harbor is about $13,000 \mathrm{~m}^{2}$ in size and is contiguous with Saint Louis Bay, Mississippi, through a $20-\mathrm{m}$ channel. Temperature and weather conditions in the harbor typically follow those of the nearby Mississippi Sound within $1-2^{\circ} \mathrm{C}$ and were downloaded from the NOAA National Data Buoy Center website for the NOAA meteorological station WYCM6-844737 located about $100 \mathrm{~m}$ from the harbor at $30^{\circ} 19^{\prime} 35^{\prime \prime} \mathrm{N}, 89^{\circ} 19^{\prime} 33^{\prime \prime} \mathrm{W}$. Carcasses were placed into a hoop net constructed of two 0.9-m diameter metal rings, attached to each other with 0.6-m-long polyethylene netting (Fig. 1A). An outer PVC hoop with floats was attached to the top hoop to ensure the upper edge of the hoop net was $\sim 10 \mathrm{~cm}$ above the waterline so that carcasses could not float out of the net (Fig. 1B). The net was tethered to a pier at the BayWaveland Yacht Club and left to float in approximately $1.5 \mathrm{~m}$ of water. Carcasses were checked daily in the morning and evening.
Water temperature and salinity were recorded by using a YSI-85 instrument, and decomposition was evaluated by visual inspection. Stage of decomposition was characterized by using previously developed coding based on the degree of bloating and percentage of the carcass above the waterline (Reneker et al., 2018) and a carcass condition classification system used by the national Sea Turtle Stranding and Salvage Network. Carcasses were classified into the following decomposition stages (codes): carcass not buoyant (code 1); carcass positively buoyant and floats (code 2.1); carcass buoyant but not fully bloated, with $50-90 \%$ of the carapace above the waterline (code 2.2); carcass severely bloated, with $90-100 \%$ of the carapace exposed and the head and neck distended (code 3.1); degassing begins, carcass becomes less buoyant, with $<90 \%$ of the carapace exposed, and the head is limp and beginning to hang (code 3.2); and carcass barely buoyant or negatively buoyant and nearly completely degassed with extensive external decomposition and disarticulation of joints (code 3.3). Daily monitoring was performed until carcasses sank or were no longer individually identified.

\section{Accumulated degree hours and statistical analyses}

We measured decomposition rate by using accumulated degree hours $(\mathrm{ADH})$, which is a measurement used in forensic science to study postmortem events and submerged human bodies (Mateus and Pinto, 2016). The unit of $\mathrm{ADH}$ measures the accumulation of thermal energy created by the biological and chemical reactions that occur throughout decomposition. The use of $\mathrm{ADH}$ allows the standardization of decomposition rate over time and among varying environmental conditions (Simmons et al., 2010). We calculated ADH by summing the hourly mean water temperatures beginning at the time a carcass was placed in the tank through the time it was in the harbor;
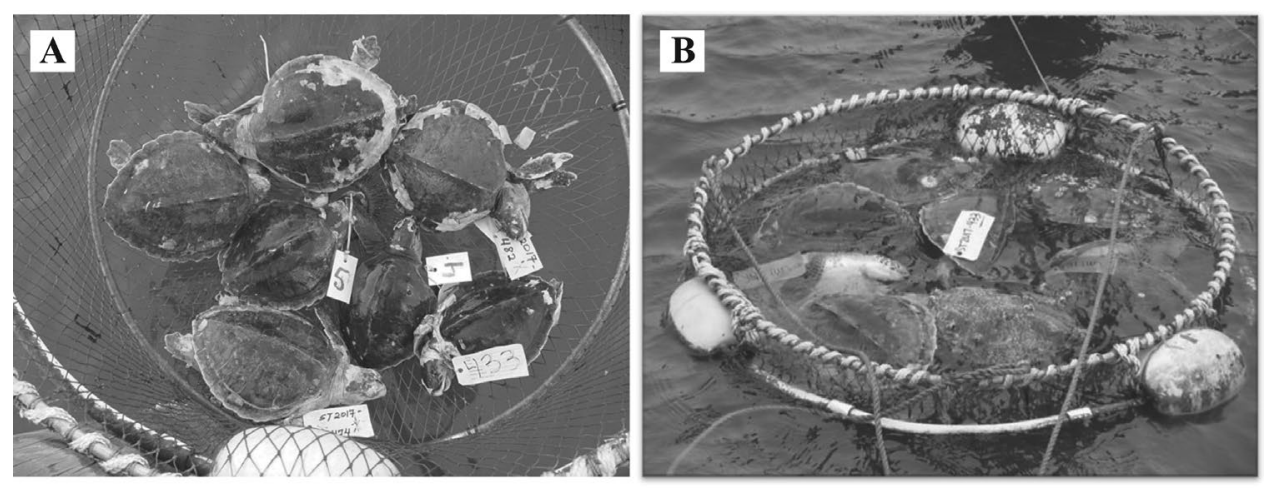

Figure 1

Images of buoyant carcasses of Kemp's ridley (Lepidocheyls kempii) and green (Chelonia mydas) sea turtles in a (A) hoop net tethered to a pier, with (B) surface floats attached, in Saint Louis Bay in Mississippi. Carcasses were left in the hoop net so that stages of decomposition could be evaluated in a natural setting. All carcasses used in this study were those of sea turtles that died during cold-stunning events in December 2017. 
temperatures were summed sequentially as a carcass progressed through each stage of decomposition. Although carcasses were exposed to ambient air and water temperatures, only water temperature was considered relevant when calculating $\mathrm{ADH}$. We made this choice because water has a much higher specific heat conductivity than air and is the primary driver of heat loss or gain in carcasses because they are always at least $50 \%$ submerged.

A generalized linear mixed model (GLMM) was used to examine the effects of species (Kemp's ridley and green sea turtles) and carcass status (unfrozen and frozen) on the number of $\mathrm{ADH}$ at specific decomposition stages. The GLMM included a random factor for each carcass to account for correlated within-subject measurements across the decomposition stages and used a heterogeneous compound symmetry covariance structure to account for nonhomogeneous variance in $\mathrm{ADH}$ with advancing decomposition stage. A Type III test of fixed effects (level of significance $=0.05$ ) was used to test for significance of species or status effects and for significant interactions between species and decomposition stage or between status and decomposition stage from the GLMM. The analysis was implemented by using the GLIMMIX procedure in the SAS/STAT component of SAS, vers 9.4 (SAS Institute Inc., Cary, NC).

\section{Results}

Under controlled conditions, a carcass achieved positive buoyancy in 48.3-154.8 h (mean: $92.5 \mathrm{~h}$ ). The $\mathrm{ADH}$ required for a carcass to float (code 2.1), as well as to reach subsequent decomposition stages for all carcasses, are presented in Table 1 and Figure 2. Tank temperature averaged $20.2^{\circ} \mathrm{C}$ and $19.2^{\circ} \mathrm{C}$ for the Kemp's ridley and green sea turtles, respectively, and the temperature required for carcasses to become positively buoyant varied considerably. The first carcass to float was an unfrozen Kemp's ridley sea turtle (791.3 $\mathrm{ADH})$, followed by a frozen green sea turtle (998.6 ADH). The last carcass to become positively buoyant was also an unfrozen Kemp's ridley sea turtle (2529.7 ADH).

Fluctuating weather temperatures greatly extended the length of the field portion of this study. Two exceptionally rare cold weather periods occurred in January. Mean daily water temperature ranged from $2.0^{\circ} \mathrm{C}$ to $24.1^{\circ} \mathrm{C}$ (mean: $12.8^{\circ} \mathrm{C}$ ). Air temperature also varied, from $-8.7^{\circ} \mathrm{C}$ to $27.2^{\circ} \mathrm{C}$ (mean: $12.2^{\circ} \mathrm{C}$ ). The use of $\mathrm{ADH}$ provided a standardized way to compare decomposition rates between carcasses under these irregular and variable conditions. Carcasses became negatively buoyant and sunk after an average of 5090.0 ADH (range: 3762.5-6528.8 ADH). The first carcass to sink was a frozen green sea turtle, and the last carcass to

\section{Table 1}

Accumulated degree hours (ADH) required for frozen and unfrozen carcasses of Kemp's ridley (Lepidochelys kempii) and green (Chelonia mydas) sea turtles to reach each stage of decomposition. All carcasses were those of sea turtles that died during cold-stunning events in Cape Cod, Massachusetts (Kemp's ridley sea turtles), and Saint Joseph Bay, Florida (green sea turtles), in December 2017. Straight carapace lengths (SCLs), measured from notch to tip, are provided. Abbreviations in the carcass ID indicate that a sea turtle was an unfrozen Kemp's ridley sea turtle (KU), frozen Kemp's ridley sea turtle (KF), unfrozen green sea turtle (GU), or frozen green sea turtle (GF). For the following decomposition stages (codes), ADH are given: carcass positively buoyant and floats (code 2.1); carcass buoyant but not fully bloated, with 50-90\% of the carapace above the waterline (code 2.2); carcass severely bloated, with $90-100 \%$ of the carapace exposed (code 3.1); degassing begins, carcass becomes less buoyant, with $<90 \%$ of the carapace exposed (code 3.2 ); and carcass barely buoyant or negatively buoyant with extensive external decomposition (code 3.3).

\begin{tabular}{lcrrrrr}
\hline & & \multicolumn{5}{c}{ ADH } \\
\cline { 3 - 7 } Carcass ID & $\begin{array}{c}\text { Length } \\
\text { (cm SCL) }\end{array}$ & Code 2.1 & Code 2.2 & Code 3.1 & Code 3.2 & Code 3.3 \\
\hline KU-474 & 27.4 & 791.31 & 2093.67 & 3745.72 & 4880.08 & 5708.79 \\
KU-475 & 26.8 & 1321.68 & 3369.66 & 4504.81 & 4973.90 & 6081.47 \\
KU-482 & 25.9 & 1744.84 & 3051.41 & 3188.46 & 4302.07 & 4688.47 \\
KU-483 & 25.9 & 2529.72 & 3452.13 & 4952.14 & 5700.09 & 6528.81 \\
KF-433 & 21.7 & 1385.12 & 2081.80 & 4082.81 & 4938.31 & 6045.88 \\
KF-435 & 23.5 & 1647.20 & 2757.11 & 3153.97 & 5123.08 & 6230.65 \\
KF-438 & 21.8 & 1470.23 & 2763.72 & 4274.19 & 5408.54 & 6237.26 \\
GU-148 & 25.6 & 1681.44 & 2423.45 & 3271.93 & 3610.29 & 4700.76 \\
GU-149 & 27.8 & 1428.75 & 2318.78 & 3304.43 & 3408.55 & 3763.42 \\
GU-151 & 25.9 & 1498.92 & 3061.84 & 3302.88 & 3407.00 & 3995.62 \\
GU-152 & 23.2 & 1533.45 & 2426.20 & 3274.68 & 3613.04 & 4305.78 \\
GF-144 & 27.7 & 998.60 & 1807.60 & 2021.79 & 2250.21 & 5003.42 \\
GF-145 & 26.9 & 1153.48 & 1863.33 & 2593.46 & 3407.67 & 3762.54 \\
GF-146 & 28.1 & 1346.19 & 2589.21 & 3299.30 & 3610.99 & 4206.61 \\
& & & & & & \\
\hline
\end{tabular}




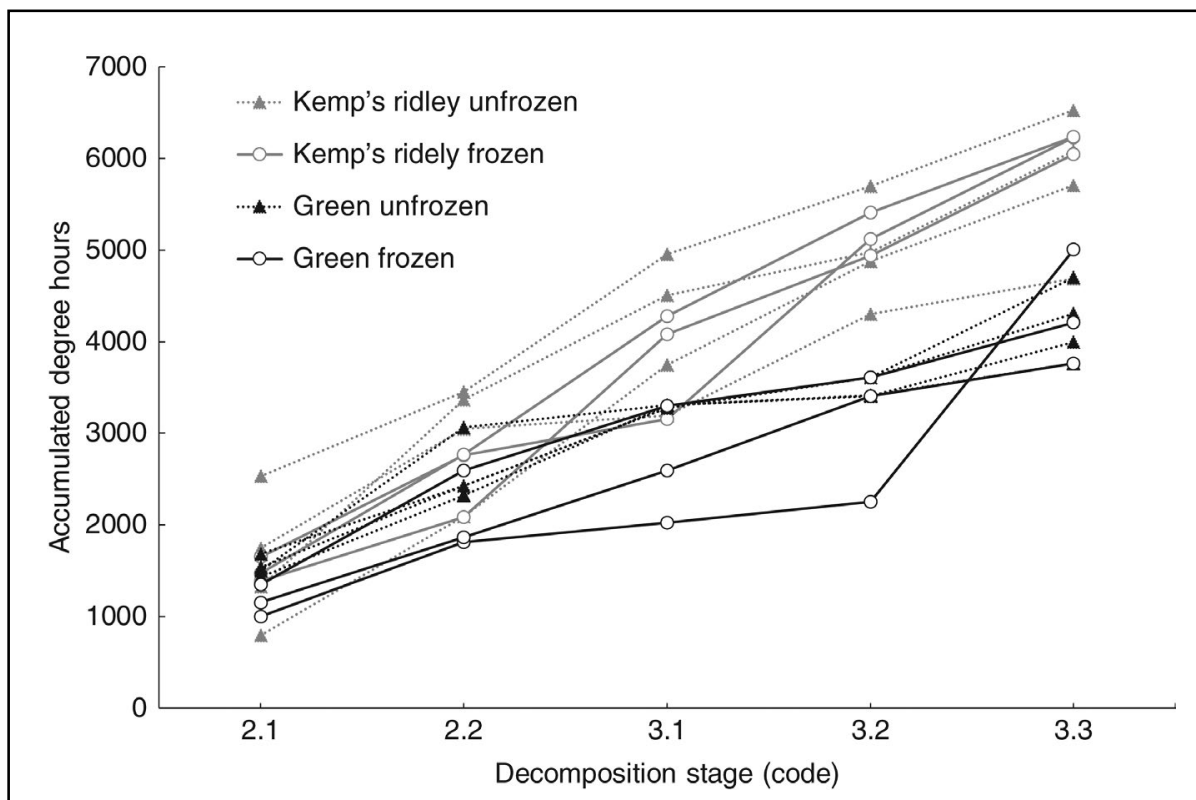

Figure 2

Accumulated degree hours, by stage of decomposition (code), for frozen (circles) and unfrozen (triangles) carcasses of Kemp's ridley (Lepidocheyls kempii) and green (Chelonia mydas) sea turtles collected in December 2017 from Cape Cod, Massachusetts, and Saint Joseph Bay, Florida, respectively. Carcasses were placed in controlled conditions in a tank with $\sim 20^{\circ} \mathrm{C}$ freshwater until they floated (code 2.1) and then placed in brackish water in a harbor in Saint Louis Bay, Mississippi, where they were exposed to ambient air and water temperatures. Carcasses were monitored through a sequence of decomposition stages until severe decomposition and loss of buoyancy occurred (code 3.3). The other decomposition stages are carcass buoyant but not fully bloated, with $50-90 \%$ of the carapace above the waterline (code 2.2); carcass severely bloated, with $90-100 \%$ of the carapace exposed (code 3.1); and degassing begins, carcass becomes less buoyant, with $<90 \%$ of the carapace exposed (code 3.2).

sink was an unfrozen Kemp's ridley sea turtle, which was also the last Kemp's ridley sea turtle that became positively buoyant.

Results of the Type III test of the GLMM fixed effects indicate a significant species effect $(P=0.0004)$ and a significant interaction of species with decomposition stage $(P<0.0001)$ on $\mathrm{ADH}$. In contrast, analysis with the Type III test of the GLMM fixed effects found that carcass status (frozen or unfrozen) had neither a significant effect $(P=0.3367)$ nor a significant interaction ( $P=0.1161)$ with decomposition stage on $\mathrm{ADH}$. The mean $\mathrm{ADH}$ for carcasses to float was 1555.7 $\mathrm{ADH}$ (standard deviation [SD] 527.3) for Kemp's ridley sea turtles and 1377.3 ADH (SD 234.1) for green sea turtles. An even greater variability occurred between the mean $\mathrm{ADH}$ required for each species to sink. Kemp's ridley sea turtles sank at 4688.5-6528.8 ADH, and green sea turtles sank at 3762.5-5003.4 ADH (Table 2).

\section{Discussion}

The duration required for carcasses of sea turtles to become positively buoyant and eventually sink was not significantly different between unfrozen and frozen carcasses. The decomposition rates varied within and between species. Significant differences were observed in decomposition rates between green and Kemp's ridley sea turtles. The initial time to float varied among carcasses considerably more and took slightly longer for Kemp's ridley sea turtles than for green sea turtles. Under nearly the same conditions, green sea turtles became buoyant and floated $8.9 \mathrm{~h}$ faster than Kemp's ridley sea turtles. Kemp's ridley and green sea turtles also differed in the mean $\mathrm{ADH}$ required to reach each decomposition stage; green sea turtles decomposed at a faster rate. These dissimilarities may be due to the diets of the 2 species and to associated differences in gastrointestinal anatomy and physiology. The longer intestine of the herbivorous green sea turtle and partially digested plant matter within the gut may lead to accelerated postmortem gas production and buoyancy in comparison to those of the carnivorous Kemp's ridley sea turtle. Moreover, green sea turtles that experience cold stunning in Florida typically have abundant digesta within their gastrointestinal tracts upon death (Foley et al., 2007); whereas, some cold-stunned Kemp's ridley sea turtles found in Massachusetts are devoid of gut contents (Innis et al., 2009). 


\section{Table 2}

Summary of accumulated degree hours (ADH) required for carcasses of Kemp's ridley (Lepidochelys kempii) and green (Chelonia mydas) sea turtles to reach positive buoyancy, float, and become negatively buoyant and sink. All carcasses were kept in a tank and submerged in $2.3 \mathrm{~m}$ of water held at $20^{\circ} \mathrm{C}$. The carcasses used in this study were those of sea turtles that died during cold-stunning events in Cape Cod, Massachusetts, and Saint Joseph Bay, Florida, in December 2017. SD=standard deviation.

\begin{tabular}{lcrrrr}
\hline & & \multicolumn{5}{c}{ ADH } \\
\cline { 3 - 6 } \multicolumn{1}{c}{ Carcass type } & size & Mean & SD & Minimum & Maximum \\
\hline Unfrozen-float & 8 & 1423.19 & 292.55 & 791.31 & 1744.84 \\
Unfrozen-sink & 8 & 4911.27 & 918.80 & 3763.42 & 6081.47 \\
Frozen-float & 6 & 1524.24 & 543.04 & 998.60 & 2529.72 \\
Frozen-sink & 6 & 5328.22 & 1174.48 & 3762.54 & 6528.81 \\
Kemp's ridley-float & 7 & 1555.73 & 527.31 & 791.31 & 2529.72 \\
Kemp's ridley-sink & 7 & 5931.62 & 601.40 & 4688.47 & 6528.81 \\
Green-float & 7 & 1377.26 & 324.09 & 998.60 & 1681.44 \\
Green-sink & 7 & 4248.31 & 468.13 & 3762.54 & 5003.42 \\
& & & & & \\
\hline
\end{tabular}

The calculation of ADH allowed standardization of temperature on the rate of decomposition and comparison between carcasses. The results of this study indicate the effectiveness of using $\mathrm{ADH}$ to measure and document the progression of sea turtle carcasses through each stage of decomposition. The extremely cold air and water temperatures to which carcasses were exposed during this study resulted in very long periods of positive buoyancy; carcasses floated for up to $65 \mathrm{~d}$. In the northern Gulf of Mexico, sea turtles are found in water temperatures of $14^{\circ} \mathrm{C}$ or higher. Results of our research indicate that under these conditions, in $2.3 \mathrm{~m}$ of water, a carcass would float for approximately 13-22 d before sinking. Ideally, field studies on the decomposition of sea turtles would occur in spring or summer when strandings of sea turtles peak. However, timing of our field experiments were constrained to winter months because of the availability of fresh carcasses salvaged during cold-stunning events. Moreover, our objective was to examine the suitability of frozen carcasses for decomposition research and for studies in which frozen carcasses are used, such as drifting and stranding studies (Reneker et al., 2018; Santos et al., 2018); our goal was not to define precise rates of decomposition under various conditions of interest.

Micozzi (1986) found that previously frozen rats had accelerated disarticulation and decomposed from the "outside-in" but that unfrozen rats decayed from the "inside-out" because of internal anaerobic decomposition and rapid growth of intestinal microorganisms. The skin and external surfaces of previously frozen rats were considerably more susceptible to invasion by insects and microorganisms than unfrozen rats. On the basis of these observations, he recommended that earlier studies should be repeated with cadavers that were not previously frozen (Micozzi, 1986). In contrast, we found no significant differences in factors of interest related to prior freezing of carcasses of sea turtles. The only appreciable difference in our study was that unfrozen carcasses floated slightly longer than frozen carcasses. If the externum had in fact decayed at a more rapid rate, the opposite effect would have occurred because gases would have escaped from disruptions in the skin, causing previously frozen carcasses to lose buoyancy more quickly. There have been too few published studies of the effects of freezing and thawing of animals on which we can base comparison of our observations with those of the Micozzi (1986) rat study. Capacities for thermoregulation and anatomic differences could affect decomposition rates and effects of prior freezing of vertebrate taxa. The internal microbiota of homeotherms may respond differently to freezing than poikilothermic reptiles. In addition, the heavily keratinized integument of reptiles may influence external taphonomic processes.

All carcasses progressed sequentially through the decomposition stages with the amount of time it took to reach a decomposition stage varying among carcasses. For example, most green sea turtles were classified as code 3.3 within $15 \mathrm{~d}$; however, a frozen green sea turtle (GF-144) required $20 \mathrm{~d}$ to reach this stage. Species, rather than carcass status (unfrozen or frozen), significantly influenced the rate of decomposition. Results of this study indicate that decomposition rates of frozen sea turtle carcasses are similar to those of fresh carcasses and that frozen carcass may be a viable alternative for studies on decomposition and in certain studies in which fresh carcasses of sea turtles otherwise would be required.

\section{Acknowledgments}

We thank the staff and volunteers from the Massachusetts and Florida Sea Turtle Stranding and Salvage Networks for 
salvaging carcasses, especially R. Prescott and K. Dourdeville from Massachusetts Audubon Wellfleet, and for helping with the fresh and frozen carcass study, K. Sampson and A. Foley for authorizing carcass use, and N. Evou for supplying carcasses. Without their dedication and response effort, this study would not have been possible. We also thank the staff and patrons of the Bay-Waveland Yacht Club for the use of their facility. This research was supported with Sea Turtle Early Restoration Project funds administered by the Regionwide Trustee Implementation Group as part of the Deepwater Horizon Natural Resource Damage Assessment.

\section{Literature cited}

Bjorndal, K. A.

1979. Cellulose digestion and volatile fatty acid production in the green turtle, Chelonia mydas. Comp. Biochem. Physiol. A 63:127-133. Crossref

1997. Foraging ecology and nutrition of sea turtles. In The biology of sea turtles (P. L. Lutz and J. A Musick, eds.), p 199-231. CRC Press, Boca Raton, FL.

Epperly, S. P., J. Braun, A. J. Chester, F. A. Cross, J. V. Merriner,

P. A. Tester, and J. H. Churchill.

1996. Beach strandings as an indicator of at-sea mortality of sea turtles. Bull. Mar. Sci. 59:289-297.

Foley, A. M., K. E. Singel, P. H. Dutton, T. M. Summers, A. E. Redlow, and J. Lessman.

2007. Characteristics of a green turtle (Chelonia mydas) assemblage in northwestern Florida determined during a hypothermic stunning event. Gulf Mex. Sci. 25:131-143. Crossref

Innis, C., A. C. Nyaoke, C. R. Williams III, B. Dunnigan, C. Merigo,

D. L. Woodward, E. S. Webe, and S. Frasca Jr.

2009. Pathologic and parasitologic findings of cold-stunned Kemp's ridley sea turtles (Lepidochelys kempii) stranded on Cape Cod, Massachusetts, 2001-2006. J. Wildl. Dis. 45:594-610. Crossref
IUCN (International Union for Conservation of Nature and

Natural Resources).

2019. The IUCN Red List of Threatened Species, vers. 2019-2. [Available from website, accessed August 2019.]

Mast, R. B., B. J. Hutchinson, E. Howgate, and N. J. Pilcher. 2005. MTSG update: IUCN/SSC marine turtle specialist group hosts the second burning issues assessment workshop. Mar. Turtle Newsl. 110:13-15.

Mateus, M., and L. Pinto.

2016. Report on the accumulated degree days and post mortem submersion interval for an infant drowning accident. J. Forensic Invest. 4(2):3. Crossref

Micozzi, M. S.

1986. Experimental study of postmortem change under field conditions: effects of freezing, thawing and mechanical injury. J. Forensic Sci. 31:953-961. Crossref

Nero, R. W., M. Cook, A. T. Coleman, M. Solangi, and R. Hardy. 2013. Using an ocean model to predict likely drift tracks of sea turtle carcasses in the north central Gulf of Mexico. Endang. Species Res. 21:191-203. Crossref

Reneker, J. L., M. Cook, and R. W. Nero.

2018. Preparation of fresh dead sea turtle carcasses for atsea drift experiments. NOAA Tech. Memo. NMFS-SEFSC$731,14 \mathrm{p}$.

Santos, B. S., D. M. Kaplan, M. A. M. Friedrichs, S. G. Barco, K. L. Mansfield, and J. P. Manning.

2018. Consequences of drift and carcass decomposition for estimating sea turtle mortality hotspots. Ecol. Indic. 84:319-336. Crossref

Simmons, T., R. E. Adlam, and C. Moffatt. 2010. Debugging decomposition data-comparative taphonomic studies and the influence of insects and carcass size on decomposition rate. J. Forensic Sci. 55:8-13. Crossref

Vass, A. A.

2001. Beyond the grave-understanding human decomposition. Microbiol. Today, November 2001.

Wallace, B. P., A. D. DiMatteo, A. B. Bolten, M. Y. Chaloupka, B. J. Hutchinson, F. A. Abreu-Grobois, J. A. Mortimer,

J. A. Seminoff, D. Amorocho, K. A. Bjorndal, et al. 2011. Global conservation priorities for marine turtles. PLoS ONE 6(9):e24510. Crossref 